\title{
Em busca de uma cidade perdida
}

\author{
Francisco Alcides do Nascimento*
}

A IDÉIA DE TRABALHAR UMA CIDADE IMAGINÁRIA não é original. Aliás, Machado de Assis trabalhou em suas crônicas sobre os costumes cariocas não apenas com uma cidade, mas com um continente inteiro. Machado de Assis, como é sabido, nunca saiu do país, contudo descrevia costumes europeus como se fosse um turista com muitas milhas de experiências. Era um turista imaginário, um observador perspicaz do real como poucos, e que sabia usar como ninguém a arte de ouvir.

Saber ouvir também é uma prática que deve ser desenvolvida por aqueles que enveredam pelo caminho da História Oral. Foi ouvindo pessoas, sobre suas vidas e a cidade onde moram, ou moravam, que nasceu a idéia de montar este texto. Nele, não se tratam de todas as cidades lembradas pelos entrevistados, mas de Teresina, a capital do Piauí. A Teresina que revelam em seus depoimentos já não existe enquanto espaço construído, e sim enquanto memória. Essa cidade poderia ser arrolada entre aquelas narradas por Ítalo Calvino (1995) em "Cidades invisíveis”. Diomira, por exemplo, era desconhecida de Marco Polo, mas, ao avistar alguns símbolos nela existentes, o viajante veneziano teve a impressão de já tê-la visto; e a razão disso era haver conhecido os símbolos ali existentes, em outras cidades por onde já havia passado.

A cidade sonhada por Antonio Saraiva deveria se transformar em centro dinâmico da economia e sociedade piauienses. Foi pensada para alavancar o progresso no Piauí e sua posição do ponto de vista

* Universidade Federal do Piauí/Núcleo de História Oral. 
geopolítico indicava-a como o motor do desenvolvimento da Província. Tenha a cidade, nascida na "Chapada do Corisco", alcançado o seu desiderato ou não, foi desejada. O homem é um ser desejante. Assim como Isidora era a cidade dos sonhos de Marco Polo, Teresina era a cidade dos sonhos de Saraiva. "A cidade sonhada o possuía jovem (...). Na praça, há o murmurinho dos velhos que vêem a juventude passar" (Calvino, 1995, p. 12). Os velhinhos da cidade que se concentram na Praça Rio Branco recordam aquela praça na qual participaram de encontros e desencontros e, de vez em quando, são obrigados a "viajar", "voltando à mocidade (...) no divino milagre da saudade". (Napoleão, 1980, p. 162).

O texto faz uso da relação entre a historia e a memória. A discussão sobre essa relação ganhou espaço nos anos 1990. As experiências individuais, como disse antes, voltaram a ser valorizadas, deixando-se para trás a idéia de que as fontes são apenas os arquivos e as bibliotecas, depositários dos documentos por excelência, como defendiam os positivistas e neo-positivistas. A paisagem, a forma da cidade, a expressão gestual das pessoas, as experiências individuais, como dizia o poeta Martins Napoleão, podem se transformar em "fonte divina de onde brota o consolo do presente, mas pode ser também fonte da infinita consciência de si mesmo" (1980, p. 62).

A história da cidade que brota dos recortes de entrevistas/depoimentos colhidos através da metodologia/técnica da História Oral será transformada em palavras escritas. As pessoas têm as suas lembranças narradas. Não podemos revivê-las porque não compartilhamos da cidade por elas descrita; partilhamos sim de uma cidade onde a relação entre a memória e o esquecimento pode ser objetivada por meio de um discurso. Não podemos esquecer, entretanto, que o espaço de uma rua ou de uma praça funcionam como detonadores das lembranças e também como documento/monumento. "Nada é vivenciado em si mesmo, mas sempre em relação aos seus arredores, às seqüências de elementos que a eles conduzem, à lembrança ou experiências passadas" (Linch, 1999, p. 2). Cada uma das pessoas ouvidas construiu associações com a cidade e a imagem que cada uma faz dela está impregnada de lembranças e significados.

O nosso objeto, como foi dito, é uma cidade imaginária e essa condição remete-nos a uma questão fundamental, qual seja, o nosso 
objeto é impalpável e por essa razão os limites temporais e espaciais são necessariamente fluidos.

O paradigma estruturalista, durante longo período, deixou na faixa da penumbra as testemunhas individuais, consideradas pouco confiáveis devido à sua grande carga de subjetividade. A preocupação recaía sobre o caráter objetivo da história. Este fato sustentou a posição dos historiadores de negar maior atenção para a relação entre história e memória. "Para, eles a memória não era confiável do ponto de vista da análise historiográfica. O exercício da escrita da história representava uma exclusão do campo da memória" (Arruda, 2000, p. 31).

Maurice Halbwachs, um dos precursores da discussão sobre a memória, enfatiza diferentes elementos que considera como estruturadores de nossa memória e também presentes na memória coletiva da qual fazemos parte. "Entre eles incluem-se os monumentos, chamados por Pierre Nora de 'lugares da memória'; Nora elenca esses lugares tais como o 'patrimônio arquitetônico e seu estilo, que nos acompanham por toda a vida, as paisagens, as datas e personagens históricos de cuja importância somos incessantemente relembrados, as tradições e costumes, certas regras de interação, o folclore e a música e por que não, as tradições culinárias"” (Pollack, 1989, p. 3).

Com relação ao primeiro aspecto, a realidade de Teresina demonstra que nem sempre os edifícios construídos servem de referência durante toda a nossa vida. Aliás, esse parece ser um problema relacionado ao Brasil inteiro, a sedução pelo novo tem nos deixado sem algumas referências. Por sua vez, um antropólogo europeu, em visita ao Brasil e passando por São Paulo, teria dito que as cidades na América Latina não envelhecem. Embora muitos acreditem que o novo foi posto em oposição ao velho e o velho é para ser destruído ou jogado fora. É provável que esteja aí a raiz do desrespeito aos homens e mulheres, que alguns dizem viver na terceira idade.

Retomando o tema em questão, Ribamar Ramos, poeta, que durante a juventude morou em Teresina, ao retornar, depois de longa temporada de ausência, teria afirmado para um amigo que não voltaria outra vez à cidade. $\mathrm{O}$ seu interlocutor teria perguntado a razão dessa decisão. A resposta foi imediata: “a Teresina do meu tempo já não existe mais. Demoliram o Café Avenida, o Bar Carvalho e seu cozinheiro espanhol não fazem mais parte da paisagem da praça Rio Branco”. 
A cidade do "tempo do poeta" é colocada em oposição à cidade visitada. Esta lhe é desconhecida e ele sente um certo estranhamento. A cidade latente em sua memória é narrada e ganha um novo suporte, a história.

A cidade de Ramos resulta do exercício de lembrar que no lugar de um estacionamento existia o Café Avenida, local onde a elite intelectual, até o início da década de 1940, juntava-se para discutir os últimos acontecimentos da cidade, do País e do mundo, e planejava transformálos de forma profunda.

Nas manhãs de domingo, os moradores do centro da cidade vestiam a melhor roupa e a elite aproveitava para apresentar as últimas novidades na moda de vestir, copiadas das revistas especializadas; o corte de cabelo à moda das musas hollywoodianas também era copiado e o palco para o desfile era a Praça Rio Branco onde está plantada a Igreja de Nossa Senhora do Amparo, a padroeira da cidade. O pároco conseguia levar para a solenidade músicos que transformavam a missa para além de um ato litúrgico.

Embora não pretendamos fazer aqui a discussão em torno da questão da memória individual e da memória coletiva, é difícil pensálas de forma independente: quem lembra é o indivíduo, porém ocorre uma espécie de negociação entre elas.

"Para que nossa memória se beneficie da dos outros, não basta que eles nos tragam seus testemunhos: é preciso também que ela não tenha deixado de concordar com suas memórias e que haja suficientes pontos de contato entre ela e as outras para que a lembrança que os outros nos trazem possa ser reconstruída sobre uma base comum" (Pollack, 1989, p. 3).

As memórias dos vários sujeitos aqui trabalhadas concordam que a cidade recordada era ainda muito pequena: os limites são descritos entre duas ruas no sentido Norte-Sul e os dois rios no sentido OesteLeste. Mas o calçamento, por exemplo, alcançava o adro da Igreja de São Benedito, construída no Alto da Jurubeba. Além desse acidente geográfico, o calçamento começa a chegar ainda nos anos de 1940, com a construção do mais antigo hospital público da cidade, depois da Santa 
Casa de Misericórdia. Esta era considerada, pelos médicos que fizeram parte do grupo que construiu e inaugurou o hospital "Getúlio Vargas", velha demais e sem recursos para atender à população de forma adequada. A penitenciária também é lembrada, às vezes, como símbolo de muitas injustiças, outras como lugar de torturas e mortes, lembranças, que teimam em voltar.

"Houve muita prisão (....) Eu fui encarregado pelo interventor de examinar as chefaturas de serviço de polícia, porque corria o boato de muitas prisões e que havia maltratos. Foi quando eu fui em nome do interventor, juntamente com outro médico, o Doutor Antenor Neiva, fazer o serviço. De fato verificamos que havia muitas prisões, muita gente presa e muitos deles maltratados, surrados, um deles até morreu logo no dia seguinte, se não me engano, um senhor Feitosa. Esse apanhou muito, sabe?” (Almeida, 1996).

Policiais militares que estavam de serviço naquela oportunidade chegaram a listar locais onde prisioneiros eram torturados para acusar adversários do Governo. Mas todos negam qualquer relação do interventor com esses crimes.

"O doutor Leônidas era um homem de muita boa fé e confiou tudo a esse cidadão. E apesar das advertências que ele recebeu muito antes, continuava. O que Evilásio estava tentando era desestabilizar, ele só foi se desvencilhar do Evilásio, pouco tempo antes de deixar o governo e ser deposto em 1945 (...) No meu entender quem provocou isso foi o Evilásio. Agora porque continuaram os incêndios até 1946? Porque continuaram? Eu acho que os incêndios, como tinha sido uma arma política muito forte, foi através dos incêndios que Teresina toda se mobilizou em torno da oposição. Interessante, a UDN sempre foi um partido de elite em toda parte do mundo" (Nunes, 1997).

Os acontecimentos de que tratam os dois trechos acima transcritos indicam como se constroem certas histórias. As duas narrativas são 
representativas daquilo que estamos chamando de memória coletiva. Mas como dissemos antes, existe uma negociação entre a memória coletiva e a memória individual. Esta é "criada a partir de impressões culturais que a organizam e, também, de impressões próprias do que é emocionalmente básico para cada um. Estas impressões se organizam numa estrutura de narrativa diferente". Um dos entrevistados conheceu o comandante da polícia, acusado de ser incendiário e a marca deixada pelo policial é a de um homem de educação esmerada, cordato na forma de tratar. Nosso entrevistado, dizia desconfiar desse comportamento. Mesmo sem poder provar, achava que o policial era responsável pelos incêndios:

"Ele [Evilásio Vilanova], Chefe Polícia, Comandante da Polícia Militar chegou aqui vindo do Pará, era amigo do meu pai (...) Meu pai tinha um relacionamento com ele porque meu pai era prefeito de Regeneração, nossa cidade lá no interior. Evilásio morava na rua Paissandú, naquele quarteirão entre a praça Pedro II e o Karnak. Ele morava no lado esquerdo de quem sobe vindo da Paissandú. (...) A evidência que se chega, que eu cheguei era de que o autor de toda essa história era o Chefe de Polícia. Porque ele fazia isso? Para impopularizar o Doutor Leônidas e assumir o seu lugar. Era muito ambicioso, eu acho que desejava, em última instância isso. (...) Então, no meu entender, quem provocou tudo isso foi o Evilásio" (Nunes, 1997).

Nesse recorte de um dos sujeitos dessa história, ele inicia tratando da relação pessoal que o pai tinha com o principal acusado pelos incêndios ocorridos em Teresina, entre 1940 e 1947, mas em seguida faz questão de frisar que tal relacionamento é decorrente do cargo que o pai ocupava na oportunidade. Chegou a vê-lo algumas vezes. A recordação permite que se aludam aos dois tipos de memória, a individual e a coletiva. Quando acusa, Evilásio Vilanova o faz dizendo que chegou àquela posição baseado em alguns argumentos empregados por aliados do governo que tinham a pretensão de encontrar um "bode expiatório". Era muito mais fácil acusar alguém que não pertencia à elite local. A tentativa de responsabilizar um integrante daquela não deu 
em nada, no sentido de macular a imagem, de colocar a sociedade contra ele, muito pelo contrário, transformou-o em vítima e tornou-o o deputado mais votado após o fim do Estado Novo. Todavia, quando afirma que Teresina transforma-se numa cidade udenista, o faz a partir de um comportamento da coletividade que permite a sua avaliação pessoal. A memória individual, segundo Halbwachs, é um ponto de vista sobre a memória coletiva, ela é apenas uma configuração individual assumida pelo cruzamento das diferentes séries de lembranças e reminiscências, emoções imaginações que compõe a memória coletiva.

A caracterização de Evilásio Vilanova como um homem ambicioso também é uma posição individual, entretanto, o discurso de que o Chefe de Polícia pretendia desestabilizar o governo de Leônidas Melo faz parte da memória política do período. Essa é uma forma de encontrar alguém que possa assumir toda a responsabilidade das aflições sofridas pela população mais pobre que termina incorporando esse discurso. Entre aqueles que tiveram as casas queimadas, quase ninguém afirma literalmente que era Evilásio Vilanova quem tocava fogo nas casas, mas diziam ouvir falar que quem tocava fogo era o Evilásio. As recordações são pessoais somente na medida em que for possível serem atravessadas por correntes de pensamento coletivo, formando uma configuração de maior complexidade que ajuda na compreensão de fatos sociais.

No recorte dessa memória, a cidade aparece de forma clara através de monumentos que ainda hoje fazem parte da paisagem de Teresina: o Palácio de Karnak, a Rua Paissandú, a Praça Pedro II são lembrados para servirem de referência dos locais onde moravam o entrevistado e o personagem do qual trata. Em determinado momento, a Rua Paissandu é confundida com a zona de prostituição existente naquele logradouro público, local sempre lembrado por aqueles que foram ouvidos nesta pesquisa.

A cidade não dispunha de muitos lugares onde a população de sexo masculino pudesse divertir-se depois das nove horas da noite, quando ela ficava às escuras. As "moças de família” voltavam para casa. A Paissandu não era apenas o local onde adolescentes faziam a iniciação sexual e aprendiam a dançar, onde os homens casados viajavam em aventuras fora de casa. Era também um espaço alegre onde amigos reuniam-se para beber cerveja; o único local aberto depois que o corneteiro 
do quartel da Polícia Militar avisava que era "hora de recolher"; local onde se reuniam aliados políticos para traçar planos para a próxima estocada no adversário ou planejar as estratégias da campanha eleitoral próxima ou em curso.

Algumas casas noturnas daquele espaço de sociabilidade ficaram na memória coletiva masculina pelo brilho de suas festas, animadas por músicos oriundos da banda de música da Polícia Militar, pela ornamentação colorida que brilhava com iluminação artificial, contrastando com a escuridão que se fazia fora dali. Pode-se apreender esse espaço com depoimentos como o do senhor Joaquim Ribeiro Magalhães (1996):

"Havia sido famosa uma tal de Rosa Banco, que já não era tão famosa. Ela já estava idosa e poucas pessoas freqüentavam sua casa, só os velhinhos costumeiros. Nesse tempo, o movimento com orquestras boas, excelentes constituídas pelos melhores músicos da polícia, à paisana, iam tocar na Raimundinha Leite. Um salão muito grande para dança, um terraço muito grande para as mesas. Todas as toalhas que cobriam as mesas eram de linho. As mulheres que dançavam trajavam roupas caríssimas e aquelas pessoas mais idosas ficavam sentadas, tomando cerveja e o assunto era a política. O assunto era ainda condenando o governo de Leônidas".

Esse lugar limpo e asseado para onde se deslocavam os mais abastados contrasta com outro espaço de prostituição onde as casas eram construídas com a palha do coco babaçu. Mulheres preparavam comida barata para vender aos homens que trabalhavam na carga e descarga dos barcos que subiam ou desciam o rio.

"Era o submundo. Era onde se juntava a prostituta mais barata, mais desprevenida, mais cabocla, mais atrasada que chegava ali dos interiores e o caboclo mais pobre que ia beber cachacinha. As bancas da Palha de Arroz, que também era conhecida por Barrinha, vendiam cachaça pura. Era pra aquele homem mais pobre, caboclo mesmo, operário pobre, o 
homem serviçal, os vigias. Que durante o dia iam gastar o seu dinheiro com aquelas mulheres, podíamos chamar de terceira, de quinta categoria. (...) A Palha de Arroz foi o lugar mais sacrificado das casas. Mas sacrificados foram outras regiões, como aqui o Cajueiro, como ali próximo à ponte do Mafuá, ali mesmo perto da estação do trem. Entrou, entrou fogo. Era um mistério" (Magalhães, 1996).

Apesar da construção de um discurso que caracteriza Teresina como uma cidade limpa, "de ruas calçadas, largas e arborizadas. Praças públicas dignas de uma grande capital, como as praças Deodoro, Rio Branco, Pedro II e João Luís" (Diário Oficial, 1941, p. 3), a cidade do discurso é aquela do centro, onde se concentram os olhares dos administradores que atendem às demandas da elite local, dos cronistas que sonham com uma cidade que pode ser comparada, na sua organização, aos principais centros do País. Mas existe outra cidade sobre a qual dificilmente se fala, e quando isso é feito é porque algum aspecto dela ganhou as páginas policiais. O nosso entrevistado olha com um certo preconceito para o local onde homens do povo trabalham e se divertem. A Barrinha, a Palha de Arroz, são locais onde o trabalhador faz o lazer que pode fazer, cria uma identidade, ao modo daqueles que freqüentam a Paissandu.

O entrevistado traça mentalmente um mapa de regiões da cidade onde habita a população pobre. Começa pela Palha de Arroz e nos informa que esta área foi a que mais sofreu com os incêndios. Argumenta que a razão era ser um lugar "perigoso", o submundo - expressão que representa o conjunto dos marginais visto como grupo organizado, mas pode significar também o conjunto daqueles que estão fora do mundo do autor do discurso - dito de outra forma, não fazem parte do mesmo lugar social daquele. Mas voltando ao mapa invisível do entrevistado, deixando a Paissandu, o próximo espaço é Cajueiro, que também possui zona de prostituição e do qual os cronistas fazem uma imagem muito ruim.

"Depois das 6 horas da noite só ia para o lado do Cajueiro quem tinha negócio. Gente da pesada. Não conheci o famoso o Pedro Toco que vivia batendo em gente a toda 
hora. Nesse tempo a pessoa que mais afligia o bairro era o Basilão dos Cajueiros, filho do ilustre Major Sotero Basílio, um rapagão de um metro e noventa e cinco a dois metros. Muito físico e bebia muito e, depois de embriagado tornava-se valente. Era o mesmo que aconteceu com o Pedro Toco que só tinha uma perna e armado de cacete encostava em alguma coisa que ele encontrasse, com sua muleta chegou uma vez a deixar prostrados mais de dez soldados da policia que o foram prender" (Magalhães, 1996).

Mesmo que haja algum exagero, os dois personagens transformaram-se em monumentos da cidade e especialmente daquele bairro. Não há morador das imediações daquela região que não tenha ouvido falar das proezas de Pedro Toco e Basilão dos Cajueiros. Mas o bairro também oferecia festas nos finais de semana e comidas típicas, a galinha caipira e a panelada podem ser citadas como exemplo. Algum tempo depois, o Estado construiu um mercado que ainda hoje é conhecido como Mercado do Cajueiro, uma forma de intervir para limpar a área, pois a cidade expandia-se para além do Barrocão.

O outro aglomerado urbano lembrado foi o Mafuá, que depois mudou de nome, em homenagem feita ao proprietário de um bar batizado como Augusto Ferro. Em virtude da expansão da cidade em direção da estrada de ferro que ligava São Luís a Teresina, nasceu uma espécie de feira livre onde os feirantes e pequenos comerciantes vendiam os seus produtos. Algum tempo depois, a Prefeitura de Teresina construiu um prédio para abrigá-los e as pessoas começaram a indicar a região como o "Mercado do Augusto Ferro". Como no Cajueiro, a intervenção visava "limpar a área". Ali também existia uma zona de prostituição - aliás, o trajeto entre a ponte sobre o Rio Parnaíba e a estação ferroviária recebeu, de um lado e de outro, casas de prostituição. Essas casas, em sua maioria, tinham a cobertura de palha, e por essa razão, quando se fala de incêndios, todos os bairros em torno da estrada são lembrados como os mais atingidos pelos incêndios.

O Bairro Piçarra nasceu como os dois outros aqui mencionados, mas, para além da estrada de ferro, uma rodovia o cortou durante um certo período. Em meados de 1930, o governo do Estado construiu uma ponte de madeira sobre o Rio Poti, e o trajeto entre esta e a Avenida 
Circular, hoje conhecida como Avenida Miguel Rosa, foi recoberto com uma camada de seixos, razão para o nome do bairro ser Piçarra.

A expansão da cidade para a zona Sul está intimamente ligada com a construção da ponte sobre o Rio Poti, mas um dos nossos entrevistados, o Sr. Benedito Amorim, destaca que existia um movimento de homens, animais e produtos alimentares colhidos nas roças existentes nas franjas da cidade. Esse movimento termina por originar uma espécie de feira livre, como a que aconteceu no Mafuá. As pessoas vendiam os produtos, como ainda hoje se faz em pequenas cidades espalhadas pelo sertão nordestino. Neste bairro, também surge um indivíduo como monumento. Amorim lembra que Maria Maxixe aproveitou o movimento de venda dos produtos hortigranjeiros e passou a servir café da manhã. Terminou, com essa atitude, sendo lembrada como fundadora do mercado da Piçarra. Não estamos tratando do edifício, hoje transformado em espaço onde se vende outro tipo de serviço, e sim de um local onde se negociavam produtos alimentícios, sob o sol ou a chuva, dependendo da estação chuvosa ou do verão.

Apesar de o bairro continuar como centro comercial, está em curso a sua transformação em bairro residencial. A construção de prédios de apartamentos pode ser um sinal dessa transformação do espaço urbano regional da cidade Os supermercados e shopping centers estão substituindo as pequenas casas de comércio, as quitandas e os quiosques mais antigos.

O crescimento urbano terminou forçando a criação de novos bairros que tiveram como origem a Piçarra; também podem ser lembrados Monte Castelo e Cristo Rei, entre outros. Mesmo assim, o Sr. Benedito Amorim demonstra uma certa relação de amor com o bairro onde nasceu. "A memória tem como característica fundante o processo reativo que a realidade provoca no sujeito. Ela se forma e opera a partir da reação, dos efeitos, do impacto sobre o grupo ou o indivíduo, formando todo um imaginário que constitui, em certa medida, uma referência permanente ao futuro" (Nora, 1995).

A cidade é sempre um organismo em transformação, pois, a cada instante, há algo mais, que o nosso campo de visão não consegue alcançar. Por essa razão, quando se busca uma cidade guardada na memória de alguns atores sociais, "constrói-se" uma cidade de determinado momento. Cada cidadão tem vastas associações com alguma parte 
de sua cidade, e as imagens que cada um guarda estão impregnadas de lembranças e significados. Portanto, cada sujeito ouvido que teve sua memória utilizada na construção dessa narrativa guarda aspectos da cidade por alguma razão. Esses variados aspectos terminam por ajudar a cada um na construção de uma cidade invisível.

\section{Referências bibliográficas}

ALMEIDA, Agenor Barbosa. Depoimento concedido a Francisco Alcides do Nascimento. Rio de Janeiro, 24/set/1996.

ARRUDA, Gilmar. Cidades e sertões: entre a história e a memória. Bauru, EDUSC, 2000.

CALVINO, Ítalo. As cidades invisíveis. São Paulo, Companhia das Letras, 1990.

CAMPELO, Aldenora. Depoimento concedido a Francisco Alcides do Nascimento. Teresina, 3/fev/1997.

FREITAS, Marcos Cezar de. Da micro-história à história das idéias. São Paulo, Cortez, 1999.

HALBWACHS, Maurice. A memória coletiva. São Paulo, Vértice, 1990.

LINCH, Kevin. A imagem da cidade. São Paulo, Martins Fontes, 1997.

MAGALHÃES, Joaquim Ribeiro. Depoimento concedido a Francisco Alcides do Nascimento. Teresina, 13/dez/1996.

NAPOLEÃO, Martins. Folhas soltas ao vento. Teresina, COMEPI, 1980.

NORA, Pierre. "Entre a memória e história: a problemática dos lugares". In: Projeto História 10. São Paulo, 1993, p. 7-28.

NUNES, Manoel Paulo. Depoimento concedido a Francisco Alcides do Nascimento. Teresina, 1/abr/1997.

POLLAK, Michel. "Memória, esquecimento, silêncio." In: Estudos Históricos. Vol. 2, N. 3, Rio de Janeiro, 1989.

. "Memória e identidade social". In: Estudos Históricos. Vol. 5, N. 10. Rio de Janeiro, 1992.

SOUSA, Benedito Amorim de. Depoimento concedido a Francisco Alcides do Nascimento. Teresina, 19/set/1997. 
Resumo: Neste artigo propõe-se montar, através de fragmentos da memória de moradores, uma cidade que já não existe. TrabaIha-se com uma viagem imaginária, onde ruas, lugares e pessoas são personagens. Os fragmentos sobre os quais falamos resultaram de pesquisa ainda não concluída, em que se utilizou a técnica/metodologia da História Oral como instrumento. Eles permitem que façamos a construção de uma narrativa a partir da representação que cada indivíduo fez da cidade, que tracemos o esboço de um mapa com ruas, praças, cinemas, bares e zona de prostituição. Ao fim e ao cabo de tal narrativa ver-se-á nascer uma cidade invisível. A preocupação maior estará voltada para o centro, espaço para onde as pessoas se deslocavam para ir ao cinema, ao clube, ao teatro, ao passeio na praça, durante o qual se mostrava a última moda. Os habitantes do sítio faziam suas preces, mas também ouviam as bandas de música do Exército e Polícia Militar tocarem jazz, blues, tango e muito pouco da música nativa. Era no centro que apareciam as novidades tecnológicas, o cinema falado, o automóvel, a motocicleta e a bicicleta, portanto, ali eram percebidos, em primeiro lugar, os símbolos da modernidade.

Palavras-chave: cidade; memória; história.

In Search for a Lost City

Abstract: This paper tries to recreate, through fragments of the memory of the locals, a city that no longer exists. An imaginary travel is performed, where streets, places and persons are characters. The so-called fragments were extracted from a research in progress, which has used the Oral History methodology as a tool. They allow us to make the construction of a narrative based on the representation that each individual has made of the city. They also allow us to draw the sketch of a map in which streets, squares, movie theaters, bars and prostitution zones appear. After all, one sees the birth of an invisible city. The focus is directed at downtown, where people used to go to movies, clubs and theater, and to walk in the squares or just show up the new fashions. The locals made their prays, but also listened to the Army and Police Music Bands, that performed jazz, blues, tango, and a few native songs. Downtown was the place where new technologies could be first seen, as the spoken cinema, the automobiles, the motorcycles and the bicycles. Thus it was the place where the symbols of modernity were first perceived.

Keywords: city; memory; history. 